\title{
Availability of laboratory diagnosis of gonorrhoea and its meaning in case reporting in Shandong province, China
}

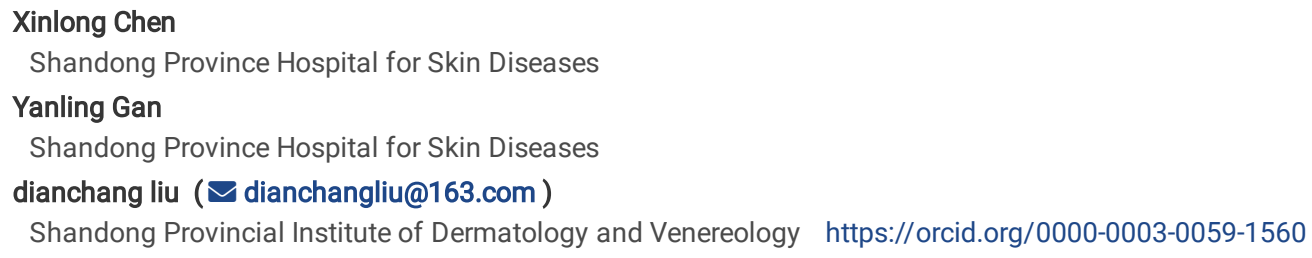

Research article

Keywords: Gonorrhea, Neisseria gonorrhoeae, Laboratory tests

Posted Date: July 1st, 2020

DOI: https://doi.org/10.21203/rs.3.rs-35168/v1

License: () (i) This work is licensed under a Creative Commons Attribution 4.0 International License. Read Full License 


\section{Abstract \\ Background}

The aim of this study is to understand the availability of laboratory diagnosis of gonorrhoea in Shandong province and its meaning in case reporting.

\section{Methods}

Two surveys were conducted among hospitals providing clinical services for sexually transmitted infection(STI) in Shandong Province in 2012 and 2018 . The availability of laboratory tests for Neisseria gonorrhoeae (NG) and distribution of reported gonorrhea cases were compared among different hospitals provided clinical services for STI in Shandong province. Descriptive analysis and Chi-square were used for statistical analysis.

\section{Results}

Smear, culture and PCR tests for NG were used among 301(74.69\%), 123(30.52\%), 43(10.67\%) hospitals in 2012 and 356(74.48\%), 176(36.82\%) and $73(15.27 \%)$ hospitals in 2018, respectively. Significant differences were observed in the availability of smear among hospitals at different levels $\left(X^{2}=12.159\right.$, $p=0.000)$ and with different affiliations $\left(X^{2}=4.551, p=0.033\right)$ in 2018. Significant differences were observed in the availability of culture and PCR tests among hospitals at different levels both in $2012\left(X^{2}=34.532, p=0.000 ; X^{2}=7.380, p=0.007\right)$ and $2018\left(X^{2}=49.820, p=0.000 ; X^{2}=21.658, p=0.000\right)$. The availability of culture and PCR tests for NG among hospitals in 2018 was higher than that in $2012\left(X^{2}=3.870, p=0.049 ; X^{2}=4.050, p=0.044\right)$. More hospitals reported gonorrhea cases in 2018 than in $2012\left(X^{2}=6.768, p=0.009\right)$. A significant difference was observed in distribution of case reporting among hospitals at different levels in $2018\left(X^{2}=6.975, p=0.008\right)$ and among different types of hospitals both in $2012\left(X^{2}=52.362, p=0.000\right)$ and 2018 $\left(X^{2}=74.478, p=\right.$ 0.000).

\section{Conclusion}

Poor availability of NG laboratory tests affects case reporting and is a crucial reason leading to high sex ratio and underreporting of gonorrhea cases in Shandong province.

\section{Trial registration}

Not applicable

\section{Background}

Gonorrhea, caused by the bacterium Neisseria gonorrhoeae (NG), is a major public health concern worldwide. It was estimated that 78 million new cases were infected by NG worldwide among population aged 15-49 years in 2012, including 34 million female and 44 million male.[1] The estimated female and male (15-49 years) prevalence for gonorrhea were 6.6\% and 3.5\% in South Africa, respectively.[2] The reported incidence of gonorrhea was higher than that of syphilis globally (25.5 versus 17.2 case per 100000 adult males) in 2014.[3]

In China, syphilis and gonorrhea belong to the second-class infectious diseases, according to the Infectious Disease Prevention Act of China.[4] The reported incidence of syphilis increased from 8.71 cases per 100, 000 residents in 2004 to 33.3 cases in 2012. In the meanwhile, the reported incidence of gonorrhea decreased from 14.21 cases per 100, 000 residents in 2004 to 7.07 in 2012. [5, 6] In addition, the male to female ratio of reported gonorrhea cases increased from 3.73:1 in 2008 to 5.51:1 in 2017.[5, 6] It was supposed that such a puzzling "scissors-like differential" phenomenon of syphilis and gonorrhea epidemic and such a high sex ratio of reported gonorrhea cases in China were unique worldwide. The real situation of gonorrhea epidemic may be distorted based on this information.

Although the reported incidence of gonorrhea has declined, it is still among the top five notifiable infectious diseases in China. In recent years, the reported incidence of gonorrhea keeps increasing from 7.96 cases per 100, 000 residents in 2013 to 9.59 in 2018.[7, 8] Gonorrhea is still one of the major infectious diseases that should be concerned. In the absence of treatment, gonorrhea can lead to pelvic inflammatory disease, ectopic pregnancy and infertility in women and prostate cancer in men.[9-11] In addition, the incidence rate of HIV had a powerful association with NG infection.[12, 13] Studies indicate that NG is rapidly becoming untreatable with decreased ceftriaxone susceptibility and high-level azithromycin resistance.[14] However, if the surveillance data cannot interpret the current situation of gonorrhea epidemic, misleading may be inevitable in policy making for gonorrhea prevention and control. Many factors may affect the integrity and accuracy of surveillance data. Gonorrhea may be asymptomatic in $40 \%$ of men and more than half of women.[15] Case reporting of gonorrhea is largely based on laboratory diagnosis in China. Availability of laboratory tests may play a vital role in gonorrhea surveillance. In addition, the reported incidence of gonorrhea is closely related to screening programmes implemented and the development of laboratory tests techniques in medical institutions. We all know that the practice of laboratory tests for NG in hospitals are associated with case reporting, but little information on how and to what extent it effects case reporting is available in China. In addition, the spread of antimicrobial-resistant NG has led to an increasing need to improve the availability of laboratory tests in hospitals. To understand the availability of laboratory tests for NG and make out its meaning in gonorrhea case reporting, we conducted two surveys among hospitals providing STI clinical service in Shandong province in 2012 and 2018, respectively. 


\section{Methods}

\section{Study site}

The study was conducted in Shandong, the third largest economically developed province in China. A total of 1549 and 2579 hospitals had been registered by 2012 and 2018, respectively, serving for about one hundred million people in the province.[16, 17]

\section{Study objects}

Hospitals providing clinical services for sexually transmitted infection (STI) in Shandong province were included in this study. All hospitals with case reporting of STI in Shandong province in the past year were defined as that provided clinical service for STI.

\section{Data collection}

We conducted two surveys in 2012 and 2018, respectively. A structured questionnaire was used in data collection. Basic information on the hospitals by levels, types, and affiliation and the types of laboratory tests for NG provided in the hospitals was collected. Trained health staff from the Centers for Diseases Control and Prevention at prefecture-level and county-level visited each hospital in their respective jurisdictions and filled in the questionnaires. The records of reported gonorrhea cases in Shandong both in 2012 and 2018 were downloaded from the China Information System for Disease Control and Prevention (CIS$\mathrm{DCP})$.

\section{Data analysis}

Valid data collected were entered into Microsoft Excel for Windows (2012) and analyzed in SPSS (version 22). The percentages of hospitals providing each laboratory tests for NG and reported gonorrhea cases were analyzed and compared by levels, types, and affiliation. Descriptive analysis and Chi-square were used for statistical analysis. $p$ values $<0.05$ was considered statistically significant.

\section{Results}

\section{General information}

Among 1549 and 2579 hospitals registered in Shandong province in 2012 and 2018, clinical service for STI were available in 410 (26.47\%) and 496 (19.23\%) hospitals, and a total of 403 and 478 valid questionnaires were collected in the two surveys, respectively. The coverage of different hospitals provided clinical services for STI was low and had been deteriorated from 2012 to 2018, excepting among specialized dermatological hospitals and maternal and child health hospitals. (Table 1)

Table 1

Percentages of surveyed hospitals in Shandong

\begin{tabular}{|c|c|c|c|c|c|c|}
\hline Categories & & $\begin{array}{l}\text { Number of hospitals } \\
\text { in } 2012\end{array}$ & $\begin{array}{l}\text { Surveyed in } 2012 \\
(\mathrm{n}, \%)\end{array}$ & $\begin{array}{l}\text { Number of hospitals } \\
\text { in } 2018\end{array}$ & $\begin{array}{l}\text { Surveyed in } 2018 \\
(n, \%)\end{array}$ & $x^{2}, p$ \\
\hline Total & & 1549 & $403(26.02)$ & 2579 & $478(18.53)$ & $32.276,0.000$ \\
\hline \multirow[t]{2}{*}{ Level } & Class III hospitals & 127 & 116(91.34) & 182 & $119(65.38)$ & $27.666,0.000$ \\
\hline & Class II and below hospitals & 1422 & $287(20.18)$ & 2397 & $359(14.98)$ & $17.376,0.000$ \\
\hline \multirow[t]{5}{*}{ Type } & $\begin{array}{l}\text { Specialized dermatological } \\
\text { hospitals }\end{array}$ & 55 & $34(61.82)$ & 48 & $43(89.58)$ & $10.471,0.001$ \\
\hline & $\begin{array}{l}\text { General western medicine } \\
\text { hospitals }\end{array}$ & 1099 & 219(19.93) & 1962 & $225(11.47)$ & $40.648,0.000$ \\
\hline & $\begin{array}{l}\text { Maternal and child health } \\
\text { hospitals }\end{array}$ & 158 & $81(51.27)$ & 162 & $107(66.05)$ & $7.214,0.007$ \\
\hline & Chinese medicine hospitals & 158 & $50(31.65)$ & 323 & $86(26.63)$ & $1.319,0.251$ \\
\hline & Other specialized hospitals & 79 & $19(24.05)$ & 84 & $17(20.24)$ & $0.344,0.558$ \\
\hline \multirow[t]{2}{*}{ Affiliation } & Public hospitals & 773 & $368(47.61)$ & 807 & $433(53.66)$ & $5.779,0.016$ \\
\hline & Private hospitals & 776 & $35(4.51)$ & 1772 & $45(2.54)$ & $6.893,0.009$ \\
\hline
\end{tabular}

\section{Availability of laboratory tests for NG in hospitals of Shandong province}

Smear, culture and PCR tests for NG were used among 301 (74.69\%), 123 (30.52\%), 43 (10.67\%) hospitals in 2012 and 356 (74.48\%), 176 (36.82\%) and 73 $(15.27 \%)$ hospitals in 2018 , respectively. Significant differences were observed in the availability of smear at different levels in $2018\left(X^{2}=12.159, p=0.000\right)$, but not in 2012. Significant differences were observed in the availability of culture and PCR tests at different levels both in $2012\left(X^{2}=34.532, p=0.000 ; X^{2}=\right.$ $7.380, p=0.007)$ and $2018\left(X^{2}=49.820, p=0.000 ; X^{2}=21.658, p=0.000\right)$. They were more available in class III hospitals than class II and below hospitals. Significant differences were observed in the availability of smear, culture and PCR tests among different type of hospitals both in $2012\left(X^{2}=35.593, p=0.000\right.$; $\left.X^{2}=27.574, p=0.000 ; X^{2}=9.666, p=0.046\right)$ and $2018\left(X^{2}=92.132, p=0.000 ; X^{2}=37.660, p=0.000 ; X^{2}=13.310, p=0.016\right)$. Smear and culture tests were 
more available among specialized dermatological hospitals and general western medicine hospitals than among other kinds of hospitals in $2012\left(X^{2}=32.450\right.$, $\left.p=0.000 ; X^{2}=23.759, p=0.000\right)$ and $2018\left(X^{2}=76.587, p=0.000 ; X^{2}=31.391, p=0.000\right)$. PCR test was more available among general western medicine hospitals than among other kinds of hospitals in $2012\left(X^{2}=6.113, p=0.013\right)$ and $2018\left(X^{2}=10.365, p=0.001\right)$. Significant differences were observed in the availability of culture test among hospitals with different affiliations in 2018 ( $X^{2}=4.551, p=0.033$ ), but not in 2012. Culture test was more available in public hospitals than private hospitals in 2018. No significant differences were observed in the availability of smear and PCR tests among hospitals with different affiliations both in 2012 and 2018.

No significant change in the availability of smear test for NG was observed among hospitals from 2012 to $2018\left(X^{2}=0.005, p=0.942\right)$. The availability of culture test for NG among hospitals in 2018 was higher than that in $2012\left(36.82 \%\right.$ vs. $\left.30.52 \%, X^{2}=3.870, p=0.049\right)$. It was significantly improved from 2012 to 2018 among general western medicine hospitals ( $36.99 \%$ vs. $\left.47.11 \%, X^{2}=4.667, p=0.031\right)$ and public hospitals $\left(30.71 \%\right.$ vs. $\left.38.34 \%, X^{2}=5.103, p=0.024\right)$. The availability of PCR test for NG among hospitals in 2018 was higher than that in $2012\left(15.27 \%\right.$ vs. 10.67\%, $\left.X^{2}=4.050, p=0.044\right)$. It was significantly improved from 2012 to 2018 among class III hospitals $\left(17.24 \%\right.$ vs. $\left.28.57 \%, X^{2}=4.261, p=0.039\right)$ and public hospitals $\left(10.60 \%\right.$ vs. $15.70 \%, X^{2}=4.482, p=$ 0.034). (Table 2)

Table 2

Availability of NG laboratory tests in hospitals of Shandong province

\begin{tabular}{|c|c|c|c|c|c|c|c|c|c|}
\hline \multirow[t]{2}{*}{ Categories } & & \multicolumn{3}{|l|}{ Smear } & \multicolumn{3}{|l|}{ Culture } & \multicolumn{2}{|l|}{ PCR } \\
\hline & & 2012(n, \%) & 2018(n, \%) & $x^{2}, p$ & 2012(n, \%) & 2018(n, \%) & $x^{2}, p$ & 2012(n, \%) & 2018(n, \%) \\
\hline Total & & 301(74.69) & $356(74.5)$ & $0.005,0.942$ & 123(30.52) & 176(36.82) & $3.870,0.049$ & $43(10.67)$ & 73(15.27) \\
\hline \multirow[t]{3}{*}{ Level } & $\begin{array}{l}\text { Class III } \\
\text { hospitals }\end{array}$ & $91(78.45)$ & 103(86.6) & $2.680,0.102$ & $60(51.72)$ & $76(63.87)$ & $3.552,0.059$ & $20(17.24)$ & $34(28.57)$ \\
\hline & $\begin{array}{l}\text { Class II and } \\
\text { below } \\
\text { hospitals }\end{array}$ & 210(73.17) & 253(70.5) & $0.571,0.450$ & 63(21.95) & $100(27.86)$ & $2.947,0.086$ & $23(8.01)$ & $39(10.86)$ \\
\hline & $x^{2}, p$ & $\begin{array}{l}1.217 \\
0.270\end{array}$ & $12.159,0.000$ & & $\begin{array}{l}34.532 \\
0.000\end{array}$ & $49.820,0.000$ & & $\begin{array}{l}7.380 \\
0.007\end{array}$ & $21.658,0.000$ \\
\hline \multirow[t]{6}{*}{ Types } & $\begin{array}{l}\text { Specialized } \\
\text { dermatological } \\
\text { hospitals }\end{array}$ & 32(91.43) & $41(95.30)$ & 1.000 & $18(52.94)$ & $22(51.16)$ & $0.024,0.877$ & $1(2.94)$ & $2(4.65)$ \\
\hline & $\begin{array}{l}\text { General } \\
\text { western } \\
\text { medicine } \\
\text { hospitals }\end{array}$ & 181(82.65) & 200(88.90) & $3.550,0.060$ & 81(36.99) & $106(47.11)$ & $4.667,0.031$ & $31(14.16)$ & 47(20.89) \\
\hline & $\begin{array}{l}\text { Maternal and } \\
\text { child health } \\
\text { hospitals }\end{array}$ & $46(56.79)$ & $48(44.90)$ & $2.625,0.105$ & $12(14.81)$ & $16(14.95)$ & $0.001,0.979$ & $4(4.94)$ & $12(11.21)$ \\
\hline & $\begin{array}{l}\text { Chinese } \\
\text { medicine } \\
\text { hospitals }\end{array}$ & $31(62.00)$ & $59(68.60)$ & $0.616,0.432$ & $8(16.00)$ & $26(30.23)$ & $3.416,0.065$ & $6(12.00)$ & 11(12.79) \\
\hline & $\begin{array}{l}\text { Other } \\
\text { specialized } \\
\text { hospitals }\end{array}$ & 11(57.89) & $8(47.10)$ & $0.423,0.516$ & $4(21.05)$ & $6(35.29)$ & 0.463 & $1(5.26)$ & $1(5.88)$ \\
\hline & $x^{2}, p$ & $\begin{array}{l}35.593 \\
0.000\end{array}$ & $92.132,0.000$ & & $27.574,0.000$ & $37.660,0.000$ & & $9.666,0.046$ & $13.310,0.016$ \\
\hline \multirow[t]{3}{*}{ Affiliation } & $\begin{array}{l}\text { Public } \\
\text { hospitals }\end{array}$ & 278(75.54) & $325(75.10)$ & $0.025,0.874$ & 113(30.71) & 166(38.34) & $5.103,0.024$ & $39(10.60)$ & $68(15.70)$ \\
\hline & $\begin{array}{l}\text { Private } \\
\text { hospitals }\end{array}$ & $23(65.71)$ & $31(68.90)$ & $0.090,0.764$ & $10(28.57)$ & $10(22.22)$ & $0.423,0.515$ & $4(11.43)$ & $5(11.11)$ \\
\hline & $x^{2}, p$ & $\begin{array}{l}1.633 \\
0.201\end{array}$ & $0.816,0.654$ & & $0.069,0.793$ & $4.551,0.033$ & & $0.023,0.880$ & $0.665,0.415$ \\
\hline
\end{tabular}

\section{Distribution and change of hospitals with gonorrhea laboratory tests and cases reporting in Shandong province}

A total of 119 (29.53\%) and 188 (39.33\%) hospitals reported gonorrhea cases in 2012 and 2018, respectively. A significant difference was observed in distribution of case reporting among hospitals with different level in $2018\left(X^{2}=6.975, p=0.008\right)$, but not in $2012\left(X^{2}=3.491, p=0.062\right)$. More class III hospitals reported gonorrhea cases than class II and below hospitals in 2018. A significant difference was observed in distribution of case reporting among different type of hospitals both in $2012\left(X^{2}=52.362, p=0.000\right)$ and $2018\left(X^{2}=74.478, p=0.000\right)$. More specialized dermatological hospitals reported gonorrhea cases than other hospitals in $2012\left(X^{2}=18.543, p=0.000\right)$. More specialized dermatological hospitals and general western medicine hospitals reported gonorrhea cases than other hospitals in $2018\left(X^{2}=58.654, p=0.000\right)$. No significant differences were observed in distribution of case reporting among hospitals with different affiliations both in $2012\left(X^{2}=2.826, p=0.093\right)$ and $2018\left(X^{2}=3.339, p=0.068\right)$. 
More hospitals reported gonorrhea cases in 2018 than in $2012\left(X^{2}=6.768, p=0.009\right)$. Specifically, more class III hospitals, class II and below hospitals, general western medicine hospitals and public hospital reported gonorrhea cases in 2018 than in $2012\left(X^{2}=4.286, p=0.038 ; X^{2}=6.086, p=0.014 ; X^{2}=15.520\right.$, $\left.p=0.000 ; X^{2}=8.523, p=0.004\right)$. (Table 3)

Table 3

Distribution and change of hospitals with gonorrhea cases reporting in Shandong province

\begin{tabular}{|c|c|c|c|c|c|}
\hline \multirow{2}{*}{$\begin{array}{l}\text { Categories } \\
\text { Total }\end{array}$} & & \multicolumn{2}{|c|}{$\begin{array}{l}\text { Hospital with case reporting in 2012(n, } \\
\%)\end{array}$} & \multirow[t]{2}{*}{$\begin{array}{l}\text { Hospital with case reporting in 2018(n, } \\
\%)\end{array}$} & \multirow{2}{*}{$\begin{array}{l}x^{2}, p \\
6.768,0.009\end{array}$} \\
\hline & & $119(29.53)$ & 188(39.33) & & \\
\hline \multirow[t]{3}{*}{ Level } & Class III hospitals & $42(36.21)$ & $59(76.47)$ & & $4.286,0.038$ \\
\hline & Class II and below hospitals & $77(26.83)$ & $129(49.58)$ & & $6.086,0.014$ \\
\hline & $x^{2}, p$ & $3.491,0.062$ & $6.975,0.008$ & & \\
\hline \multirow[t]{6}{*}{ Types } & $\begin{array}{l}\text { Specialized dermatological } \\
\text { hospitals }\end{array}$ & $21(61.76)$ & $24(55.81)$ & & $0.277,0.599$ \\
\hline & General western medicine hospitals & $78(35.62)$ & $122(54.22)$ & & $15.520,0.000$ \\
\hline & Maternal and child health hospitals & $3(3.70)$ & $9(8.41)$ & & $1.710,0.191$ \\
\hline & Chinese medicine hospitals & $16(32.00)$ & $31(36.05)$ & & $0.229,0.632$ \\
\hline & Other specialized hospitals & $1(5.26)$ & $2(11.76)$ & & 0.593 \\
\hline & $x^{2}, p$ & $52.362,0.000$ & $74.478,0.000$ & & \\
\hline \multirow[t]{3}{*}{ Affiliation } & Public hospitals & $113(30.71)$ & $176(40.65)$ & & $8.523,0.004$ \\
\hline & Private hospitals & $6(17.14)$ & $12(26.67)$ & & $1.024,0.312$ \\
\hline & $x^{2}, p$ & $2.826,0.093$ & $3.339,0.068$ & & \\
\hline
\end{tabular}

Among hospitals reported cases of gonorrhea in 2018, 95 reported female gonorrhea cases. More hospitals with culture or PCR tests available reported female cases of gonorrhea than those without $\left(67.37 \%\right.$ vs. $\left.32.63 \% ; X^{2}=7.733, p=0.005\right)$.

\section{Discussion}

In this study, we evaluated the capacity of clinical services for STI in Shandong province, especially of laboratory diagnosis of gonorrhea. We found that the number of hospitals providing STI clinical service increased but the proportion decreased in the past six years. The total number of registered hospitals largely increased in the past six year, but the coverage of clinical service for STI did not increase correspondingly. Especially, the number of private hospitals increased rapidly but the proportion of providing STI clinical service was very low and decreased. Although the proportion of specialized dermatological hospitals increased, their number was small and decreased. Public general western medicine hospitals are still playing a core role in STI clinical service in Shandong province. The proportion of hospitals providing STI clinical service was still as low as $18.53 \%$ in 2018 , indicating that much room needs to be improved in availability of STI clinical service in Shandong province.

Among hospitals providing STI clinical service, the availability of laboratory tests for NG was low. Among hospitals surveyed in 2018 , more than $1 / 4$ could not provide smear test for NG, more than $3 / 5$ could not provide culture test, and more than $5 / 6$ could not provide PCR test. With the implementation of China's Syphilis Prevention and Control Program (2010-2020), the availability of syphilis tests and screening programs have been enhanced, the reported incidence of syphilis have increased quickly, nevertheless, the availability of laboratory tests for NG kept low. We suppose that this may be one of the rational explanations of "scissors-like differential" phenomenon of syphilis and gonorrhea epidemic in China. In 1990s, the reported incidence of gonorrhea was much higher than syphilis and kept increasing to its peak in 1999, then went down. A new criterion for diagnosis of gonorrhea implemented in 2007, defining gonorrhea case based on pathogenic test instead of clinical examination, and the role of laboratory tests has been emphasized since then.

Although most hospitals could provide smear test female gonorrhea cases could not be diagnosed by smear according to the criterion for diagnosis of gonorrhea issued by the National Health Commission of China. Diagnosis of female gonorrhea cases relies on culture or PCR tests of NG. Most female cases may be underdiagnosed and underreported due to low availability of culture and PCR tests, which may lead to the high sex ratio of reported gonorrhea case in China.

It is recommended that all sexually active women aged 24 years or younger and older women at high risk of gonorrhea and chlamydia infection should be screened with PCR test.[18] Maternal and child health hospitals should play an important role in NG screening among the female. The laboratory tests for NG were less available in maternal and child health hospitals than specialized dermatological hospitals and general western medicine hospitals, and no improvement was achieved in the past six years, which may lead to low reported female incidence of gonorrhea and high sex ratio in Shandong province. Although smear test is less sensitive to women, it is still the main method for NG screening even in maternal and child health hospitals in Shandong province. More gonorrhea cases were reported in male than female as well in some countries with high availability of PCR test for NG.[19, 20] However, the reasons may be different. Usually, men who have sex with men (MSM) are the core high risk population with high incidence of gonorrhea in those countries.[21-23] 
We confirmed that the availability of laboratory tests of NG is related to case reporting of gonorrhea. The distribution of hospitals with gonorrhea case reporting was consistent with that of hospitals where laboratory tests were available. The availability of culture and PCR tests has been improved in Class III hospitals, general western medicine hospitals and public hospitals from 2012 to 2018 . Accordingly, the proportion of hospitals with case reporting increased significantly in those hospitals. Earlier study also found that the increasing number of gonorrhea cases was related to the PCR testing rate.[24] Diagnosis of female gonorrhea cases relies on culture or PCR tests of NG. Insufficient of laboratory tests may lead to underdiagnosed and underreported of gonorrhea, especially for female cases, in Shandong province. In addition, more than $74 \%$ of surveyed hospitals could provide smear test for NG at least both in 2012 and 2018 , however, less than $40 \%$ reported cases of gonorrhea. It indicates that availability of laboratory tests is not the exclusive factor related to case reporting. We found by interview with doctors that another factor leading to under diagnosis and under reporting of gonorrhea may be the low awareness of gonorrhea screening by clinical doctors. Many infections of NG have no symptoms and most cases may never be diagnosed without screening. In Canada, midwives, family physicians and generalist obstetricians tested $93.8 \%, 91.4 \%$ and $88.5 \%$ of their patients respectively.[25] Low availability of NG screening may lead to missed diagnosis and underreporting of gonorrhea in China.

Many factors may affect availability and use of laboratory tests of NG. Smear test is the most commonly used method for NG screening. It is rapid, convenient and inexpensive. The sensitivity and specificity of smear were high for symptomatic males, but low for female.[26-28] The culture method has high sensitivity and specificity and is the "gold standard" for the diagnosis of gonorrhea.[29] But, it needs higher requirements with meticulous sample collection, transport and nutrient medium than other methods.[30,31] PCR test offers very high sensitivity and specificity of detection, above $90 \%$ and $99 \%$, respectively. It is recommended for detection of urogenital infections in women and men with and without symptoms.[32] For rectal gonorrhea and pharyngeal gonorrhea, testing positive was more obtained by PCR than culture.[33] However, higher requirements in equipment and technicians than smear and culture may restrict its wide use. In California, the proportion of gonorrhea testing performed using PCR test increased from 1-59\% and culture test decreased from $42-10 \%$ of all gonorrhea testing.[34] In contrast, the availability of PCR test was still as low as $15 \%$ among hospitals providing STI clinical service in Shandong province in 2018.

Drug-resistance of NG is increasing in China and other countries in the world.[35-37] By far, spread of drug-resistant NG has become a threat to effectively controlling gonorrhea in the world and led to an increasing need for antimicrobial-susceptibility testing. Low availability of laboratory tests of NG and antibiotics abuse may further aggravate drug-resistant. In a survey of 57 countries that responded, only 14 countries reported having antenatal CT or NG screening policies.[38] National level policies to support routine screening for CT or NG infection to prevent adverse pregnancy and newborn outcomes are uncommon.

Some efforts are needed to improve the screening and reporting of gonorrhea in Shandong. Firstly, increase accessibility of STI clinical services by integrating the prevention and management of STI into the broader agendas of HIV, sexual and reproductive health, and other key platforms. Secondly, accelerate accessibility to innovations through the development of point-of-care (POC) testing. The overall rate of agreement and negative percentage agreement with POC were $97.8 \%$ and $100 \%$ respectively, for NG compared with NAAT methods.[39] WHO also advocated the development of POC testing as a critical step within STI cascade and continuum of services. POC testing for urogenital infections might improve case-finding and infection management and is feasible in resource-poor settings.[40] Integration of POC testing can mitigate the transmission and burden of STI.[41] Thirdly, strengthen training of clinicians and scale up STI interventions. Lack of training for clinicians was one of the important barriers for performing STI testing.[42] The testing rate increased from 7.90$17.86 \%$ among university campus through education.[43] Finally, strengthen quality assurance of NG laboratory tests. According to a survey, Only $5 \%$ of the laboratories met or surpassed the lowest quality standards defined by the WHO/AFRO-derived laboratory strengthening tool in Kampala.[44]

\section{Limitations Of The Study}

There are some limitations in the study. First, the investigation was conducted in a province of China, and generalization of the results should be cautious. Second, many other factors may affect reporting and sex ratio of gonorrhea incidence besides the availability of laboratory tests for NG.

\section{Conclusions}

In conclusion, poor availability of NG laboratory tests affects case reporting and is a crucial reason leading to high sex ratio and underreporting of gonorrhea cases in Shandong province. More efforts are needed to improve the availability of NG laboratory tests in order to effectively control of gonorrhea.

\section{Abbreviations}

CISDCP: China Information System for Disease Control and Prevention; CT: Chlamydia trachomatis; MSMヌMen who have sex with men; NG: Neisseria gonorrhoeae; POC囚Point-of-care; STI: Sexually transmitted infection.

\section{Declarations}

\section{Ethics approval and consent to participate}

This study was approved by the institutional review board at the Shandong Provincial Institute of Dermatology and Venereology.

\section{Consent for publication}

Not applicable 
The datasets used and/or analyzed during the current study are available from the corresponding author on reasonable request.

\section{Competing interests}

The authors declare that they have no competing interests.

\section{Funding}

This work was supported by the Shandong Provincial Key R\&D Plan (2018GSF118062). The funding body was not involved in the collection, analysis and interpretation of data, nor in the writing of manuscripts.

\section{Authors' contributions}

DL who is corresponding author obtained funding and designed the study. XC is first authors. DL and XC collected and analyzed the data, drafted the manuscript. YG contributed to the

interpretation of the results and critical revision of the manuscript for important intellectual content and approved the final version of the manuscript. All authors have read and approved the final manuscript. DL is the study guarantors.

Acknowledgements The authors thank the Centers for Diseases Control and Prevention at different level and every participant enrolled in this study in Shandong province.

\section{References}

1. Newman L, Rowley J, Vander Hoorn S, Wijesooriya NS, Unemo M, Low N, et al. Global Estimates of the Prevalence and Incidence of Four Curable Sexually Transmitted Infections in 2012 Based on Systematic Review and Global Reporting. PLoS One,2015. 10(12):e0143304.

2. Kularatne RS, Niit R, Rowley J, Kufa-Chakezha T, Peters RPH, Taylor MM, et al. Adult gonorrhea, chlamydia and syphilis prevalence, incidence, treatment and syndromic case reporting in South Africa: Estimates using the Spectrum-STI model, 1990-2017. PLoS One, 2018.13(10):e0205863.

3. World Health Organization. Report on global sexually transmitted infection surveillance 2015. http://apps.who.int/iris/bitstream/handle/10665/249553/9789241565301-eng.pdf;jsessionid=96A8822559F95D8828C0495DD30FBFC3? sequence=1.

4. National People's Congress. The Infectious Disease Prevention Act (The 17th Presidential Decree of the People's Republic of China).http://www.gov.cn/gongbao/content/2004/content_62975 (available 2017-09-11).

5. The China Disease Prevention and Control Center, Overview of the national legal infectious disease epidemic in 2004. http://www.nhc.gov.cn/jkj/s2907/new_list_25.shtml (Available 2006-02-18).

6. The China Disease Prevention and Control Center, Overview of the national legal infectious disease epidemic in 2012. http://www.nhc.gov.cn/jkj/s2907/new_list_8.shtml (Available 2013-03-15).

7. The China Disease Prevention and Control Center, Epidemic situation of statutory infectious diseases in China in 2013. http://www.nhc.gov.cn/jkj/s3578/201402/26700e8a83c04205913a106545069a11.shtml (Available 2014-02-13)

8. The China Disease Prevention and Control Center, Overview of the epidemic situation of statutory infectious diseases in China in 2018. http://www.nhc.gov.cn/jkj/s3578/201904/050427ff32704a5db64f4ae1f6d57c6c.shtml (Available 2019-04-24).

9. Wang YC, Chung $\mathrm{CH}$, Chen JH, Chiang MH, Ti-Yin, Tsao $\mathrm{CH}$, et al. Gonorrhea infection increases the risk of prostate cancer in Asian population: a nationwide population-based cohort study. Eur J Clin Microbiol Infect Dis,2017. 36(5):813-821.

10. Brunham RC, Gottlieb SL, Paavonen J. Pelvic inflammatory disease.N Engl J Med 2015. 372:2039-2048.

11. Moore MS, Golden MR, Scholes D, Kerani RP. Assessing Trends in Chlamydia Positivity and Gonorrhea Incidence and Their Associations With the Incidence of Pelvic Inflammatory Disease and Ectopic Pregnancy in Washington State, 1988-2010. Sex Transm Dis, 2016. 431, 2-8

12. Fleming DT, Wasserheit JN. From epidemiological synergy to public health policy and practice: the contribution of other sexually transmitted diseases to sexual transmission of HIV infection. Sex Transm Infect, 1999. 75(1):3-17.

13. Andreatos N, Grigoras C, Shehadeh F, Pliakos EE, Stoukides G, Port J, et al. The impact of HIV infection and socioeconomic factors on the incidence of gonorrhea: A county-level, US-wide analysis. PLoS ONE,2017. 12(9): e0183938.

14. Katz AR, Komeya AY, Kirkcaldy RD, Whelen AC, Soge OO, Papp JR, et al. Cluster of Neisseria gonorrhoeae Isolates With High-level Azithromycin Resistance and Decreased Ceftriaxone Susceptibility, Hawaii, 2016. Clin Infect Dis, 2017. 65(6):918-923.

15. Handsfield HH, Lipman TO, Harnisch JP, Tronca E, Holmes KK. Asymptomatic gonorrhea in men. Diagnosis, natural course, prevalence and significance. N Engl J Med, 1974. 290(3):117-23.

16. Health and Family Planning Commission of Shandong Province. 2018 Shandong province health and family planning development statistics bulletin.http://wsjkw.shandong.gov.cn/jksd/tjsj_763/zytjbg/201908/t20190801_2335002.html (Available 2019-08-01).

17. Health and Family Planning Commission of Shandong Province. 2012 Shandong province health and family planning development statistics bulletin.http://wsjkw.shandong.gov.cn/jksd/tjsj_763/zytjbg/201305/t20130530_591620.html (Available 2013-05-30).

18. Audrey T, Adam SC. Screening for Gonorrhea, Chlamydia, and Hepatitis B. 2016, JAMA, 315(12): p. 1278-9.

19. Centers for Disease Control and Prevention. Sexually Transmitted Disease Surveilance 2017. https://www.cdc.gov/std/stats17/Gonorrhea.htm.

20. Choudhri Y, Miller JP, Sandhu J, Leon A, Aho J. Gonorrhea in Canada, 2010-2015. Can Commun Dis Rep, 2018. 44(2), 37-42.

Page $7 / 8$ 
21. Loenenbach A, Dudareva-Vizule S, Buder S, Sailer A, Kohl PK, Bremer V. Laboratory practices: diagnostics and antibiotics resistance testing of Neisseria gonorrhoeae in Germany. Bundesgesundheitsblatt, Gesundheitsforschung, Gesundheitsschutz, 2015. 58(8): 866-874.

22. Garrett TA, Davies-Cole J, Furness B. Laboratory Capacity for Antimicrobial Susceptibility Surveillance of Neisseria gonorrhoeae-District of Columbia, 2007-2012. Sex Transm Dis, 2015. 42(8): 413-6.

23. Peterman TA, O'Connor K, Bradley HM, Torrone EA, Bernstein KT. Gonorrhea Control, United States, 1972-2015, A Narrative Review. Sex Transm Dis, 2016. 43(12):725-730.

24. Wang Honglin, Cai Yumao, Lan Lina. Factors associated with the raising prevalence of gonorrhea in Shenzhen in 2016. Inter J Epidemiol Infect Dis, 2019, 46(4):301-305.

25. Vainder M, Kives S, Yudin MH. Screening for Gonorrhea and Chlamydia in Pregnancy: Room for Improvement. J Obstet Gynaecol Can. 2019. 41(9):12891294.

26. Centers for Disease Control and Prevention, Recommendations for the Laboratory-Based Detection of Chlamydia trachomatis and Neisseria gonorrhoeae2014. MMWR Recomm Rep, 63(2):1-19.

27. Koumans EH, Johnson RE, Knapp JS, St Louis ME. Laboratory testing for Neisseria gonorrhoeae by recently introduced nonculture tests: a performance review with clinical and public health considerations. Clin Infect Dis, 1998. 27:1171-80.

28. Workowski KA, Berman S, Sexually Transmitted Diseases Treatment Guidelines, 2010, MMWR Recomm Rep, 2010. 59:1-116.

29. Drafting Group of National Center for STD Control, China CDC; Chinese guidelines for laboratory diagnosis of gonorrhea, Inter J Epidemiol Infect Dis, 2019, 46(4).

30. Boiko I, Golparian D, Krynytska I, Unemo M. High prevalence of Chlamydia trachomatis, Neisseria gonorrhoeae and particularly Trichomonas vaginalis diagnosed using US FDA-approved Aptima molecular tests and evaluation of conventional routine diagnostic tests in Ternopil, Ukraine. APMIS, 2019. 127(9):627-634.

31. Visser $M$, van Westreenen $M$, van Bergen J, van Benthem BHB. Low gonorrhoea antimicrobial resistance and culture positivity rates in general practice: a pilot study. Sex Transm Infect, 2020. 96(3):220-222.

32. Centers for Disease Control and Prevention. Recommendations for the Laboratory-Based Detection of Chlamydia trachomatis and Neisseria gonorrhoeae2014. Recommendations and Reports.2014;63(2).

33. Cornelisse VJ, Chow EP, Huffam S, Fairley CK, Bissessor M, De Petra V, et al. Increased Detection of Pharyngeal and Rectal Gonorrhea in Men Who Have Sex With Men After Transition From Culture To Nucleic Acid Amplification Testing. Sex Transm Dis,2017. 44(2).

34. Ahrens K, Bradbury KJ, Bauer HM, Samuel MC, Gould G, Higgins C, et al. Trends in the use of sexually transmitted disease diagnostic technologies in California, 1996-2003. Sex Transm Dis, 2007. 34(7): 513-8.

35. Chen SC, Yin YP, Dai XQ, Unemo M, Chen XS. First nationwide study regarding ceftriaxone resistance and molecular epidemiology of Neisseria gonorrhoeae in China. J Antimicrob Chemother, 2016. 71(1):92-9.

36. Zheng H, Wu X, Huang J, Qin X, Xue Y, Zeng W, et al. The prevalence and epidemiology of plasmid-mediated penicillin and tetracycline resistance among Neisseria gonorrhoeae isolates in Guangzhou, China, 2002-2012. BMC Infectious Diseases, 2015, 15(1): 412-412.

37. Tanaka M, Furuya R, Irie S, Kanayama A, Kobayashi I. High Prevalence of Azithromycin-Resistant Neisseria gonorrhoeae Isolates With a Multidrug Resistance Phenotype in Fukuoka, Japan. Sex Transm Dis, 2015. 42(6), 337-41.

38. Medline A, Joseph Davey D , Klausner J D . Lost opportunity to save newborn lives: variable national antenatal screening policies for Neisseria gonorrhoeae and Chlamydia trachomatis. Int J STD AIDS, 2017. 28(7): 660-666.

39. Badman SG, Willie B, Narokobi R, Gabuzzi J, Pekon S, Amos-Kuma A, et al. A diagnostic evaluation of a molecular assay used for testing and treating anorectal chlamydia and gonorrhoea infections at the point-of-care in Papua New Guinea. Clin Microbiol Infect, 2019. 25(5):623-627.

40. Verwijs MC, Agaba SK, Sumanyi JC, Umulisa MM, Mwambarangwe L, Musengamana V, et al. Targeted point-of-care testing compared with syndromic management of urogenital infections in women (WISH): a cross-sectional screening and diagnostic accuracy study. Lancet Infect Dis, 2019. 6:658-669.

41. Toskin I, Govender V, Blondeel K, Murtagh M, Unemo M, Zemouri C, et al. Call to action for health systems integration of point-of-care testing to mitigate the transmission and burden of sexually transmitted infections. Sex Transm Infect, 2020. 0:1-6.

42. Ong JJ, Peng M, Zhu S, Lo YJ, Fairley CK, Kidd MR, et al. Opportunities and barriers to STI testing in community health centres in China: a nationwide survey. Sex Transm Infect,2017. 93(8):566-571.

43. Myers A, McCaskill SP, VanRavenstein K. Improving STD Screening Rates on a University Campus. J Community Health, 2017. 42(6): 1247-1254.

44. Elbireer AM, Jackson JB, Sendagire H, Opio A, Bagenda D, Amukele TK. The Good, the Bad, and the Unknown: Quality of Clinical Laboratories in Kampala, Uganda. Plos One, 2013, 8(5):e64661.

\section{Supplementary Files}

This is a list of supplementary files associated with this preprint. Click to download.

- Questionnaire.docx 